\title{
The Status of Spectroscopic Data for the Exoplanet Characterisation Missions
}

\author{
Jonathan Tennyson · Sergei N. Yurchenko
}

Received: May 1, 2022/ Accepted: date

\begin{abstract}
The status of laboratory spectroscopic data for exoplanet characterisation missions such as EChO is reviewed. For many molecules $\left(\mathrm{eg} \mathrm{H}_{2} \mathrm{O}, \mathrm{CO}, \mathrm{CO}_{2}, \mathrm{H}_{3}^{+}, \mathrm{O}_{2}\right.$, $\mathrm{O}_{3}$ ) the data are already available. For the other species work is actively in progress constructing this data. Much of the is work is being undertaken by ExoMol project (wWw.exomol.com). This information can be used to construct a mission-specific spectroscopic database.
\end{abstract}

Keywords Infrared $\cdot$ Molecular line lists $\cdot$ rotation-vibration

\section{Introduction}

The EChO (Exoplanet Characterisation Observatory) mission [1] aims to use spectroscopy to probe the atmospheres of a range of transiting exoplanets. To ensure the success of EChO, or another mission with similar aims, it is important to have access to the necessary spectroscopic data which will provide inputs to radiative transport models used for the atmospheres of exoplanets such as implemented in the codes NEMESIS [2] and TAU [3], as well as other models such as those of Madhusudhan and Seager [4]. Codes designed to model the atmospheres of brown dwarfs and cool stars, such as ATLAS [5], MARCS [6], PHOENIX [7], BT-Settl [8] and VSTAR [9], require similar molecular data. The combination of a comprehensive spectroscopic database and a physically realistic model are essential for both interpretting the observational data and studying the evolution of the objects.

For our solar system, the spectroscopic data for modelling radiative transport in planetary atmospheres is provided by specialist data bases, such as HITRAN [10,11] and GEISA [12], which have been compiled and refined over many years using the data recorded at or about room temperature, defined by HITRAN as 296 K. However those exoplanets that will be the subject of early characterisation studies are likely to be considerably hotter than the atmospheres of solar systems planets. Elevated

Department of Physics and Astronomy, University College London, London WC1E 6BT, UK 
temperatures lead to both a huge increase in the number of molecular transitions that need to be considered and, possibly, changes in the atmospheric composition. It is therefore necessary to ensure that all data required for modelling such atmospheres will be in place.

There are spectroscopic databases available for hot molecules. Kurucz has compiled data sets for models of (cool) stellar atmospheres for many years [13]. However data are lacking for many species in these compilations and are approximate for others. More recently the high temperature version of HITRAN, known has HITEMP, has been updated [14]. The HITEMP data can be considered as comprehensive and reliable, but is only available for five species: water, $\mathrm{CO}_{2}, \mathrm{CO}, \mathrm{OH}$ and NO . The ExoMol project [15] is currently in progress and has the specific aim of providing spectroscopic data applicable for a large range for temperatures for studying exoplanet atmospheres.

Hot molecules require significantly more data to simulate spectra at high temperatures. Fig. 1 1 illustrates the importance of the hot transitions of $\mathrm{CH}_{4}$ missing in HITRAN for modelling the hot $(T=1200 \mathrm{~K})$ absorption. This figure shows an absorption spectrum simulated using the HITRAN and theoretical 10 to 10 line lists [16]. The HITRAN spectra, being based on the room temperature data, suffers from lacking the hot transitions leading to significant underestimation of the opacity at elevated temperatures, by about $50 \%$ at $1000 \mathrm{~K}$ for example.

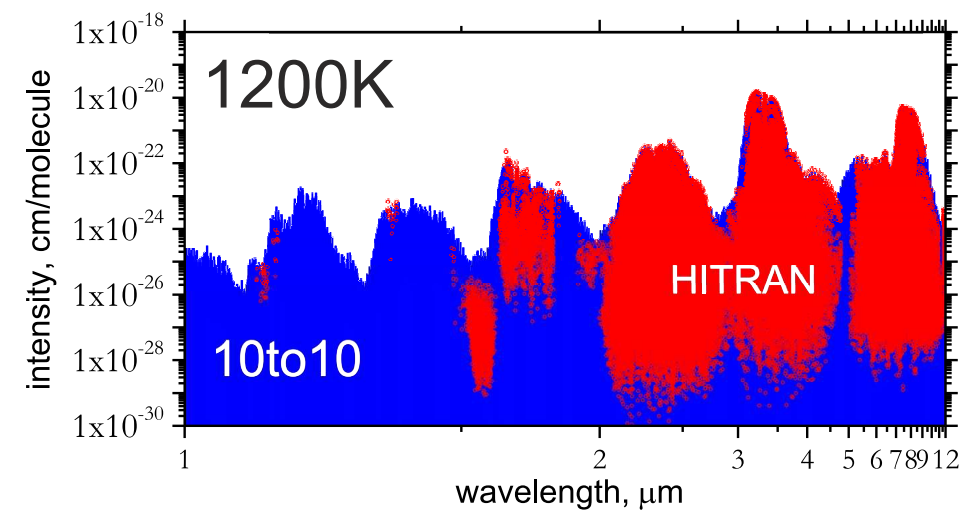

Fig. 1 Absorption spectra of $\mathrm{CH}_{4}$ at $T=1200 \mathrm{~K}$ simulated using data from HITRAN 2012 [11] and the 10 to10 [16] line list generated as part of the ExoMol project.

Table 1 is taken from the initial EChO proposal as submitted in the autumn of 2010 [17], see also the $2013 \mathrm{EChO}$ assessment study [18]. The table summarises the main spectral features that EChO planned to probe. The status of the data for each of these species is discussed in the next section. In addition this original compilation [18] we have also identified several potentially important spectral features for the molecules in question, listed in the last column of Table 1 Given the rapid progress in exoplanetary research and, in particular, the discovery of new, unanticipated classes 
of exoplanets, it is possible that data on further species, not anticipated in the initial proposal will also be required. The status of some of these data is discussed in section 3.

Table 1 Main spectral features between 0.4 and $16 \mu \mathrm{m}$. The asterisk indicates the molecular/atomic species already detected in the atmospheres of exoplanets. At wavelengths shorter than $2 \mu \mathrm{m}$ spectroscopic data are often not complete, so that the use of this region is much more difficult for band identification and analysis. The main bands are illustrated in bold.

\begin{tabular}{|c|c|c|c|c|c|}
\hline & $0.4-1 \mu \mathrm{m}$ & $1-5 \mu \mathrm{m}$ & $5-11 \mu \mathrm{m}$ & $11-16 \mu \mathrm{m}$ & Additional $^{a}$ \\
\hline$R$, baseline & 300 & 300 & $\geq 30$ & 30 & \\
\hline$R$, desired & 300 & 300 & 300 & 300 & \\
\hline \multicolumn{6}{|l|}{ Species } \\
\hline $\mathrm{C}_{2} \mathrm{H}_{2}$ & - & $1.52, \mathbf{3 . 0}$ & 7.53 & 13.7 & 2.5 \\
\hline $\mathrm{C}_{2} \mathrm{H}_{4}$ & - & $\mathbf{3 . 2 2}, 3.34$ & $6.9, \mathbf{1 0 . 5}$ & - & \\
\hline $\mathrm{C}_{2} \mathrm{H}_{6}$ & - & 3.4 & - & 12.1 & 6.7 \\
\hline $\mathrm{CH}_{3} \mathrm{D}$ & - & $3.34,4.5$ & $6.8,7.7,8.6$ & - & \\
\hline$* \mathrm{CH}_{4}$ & $\begin{array}{l}0.48,0.57 . \quad 0.6,0.7 \\
0.79,0.86\end{array}$ & $\begin{array}{l}1.65,2.2,2.31,2.37, \\
\mathbf{3 . 3}\end{array}$ & 7.7 & - & 6.5 \\
\hline$* \mathrm{CO}$ & - & $1.57,2.35,4.7$ & - & - & 1.19 \\
\hline${ }^{*} \mathrm{CO}_{2}$ & - & $\begin{array}{l}1.21,1.57,1.6,2.03, \\
4.25\end{array}$ & - & 15.0 & $1.43,2.7$ \\
\hline $\mathrm{FeH}$ & $0.6-1$ & $1-2$ & - & - & \\
\hline $\mathrm{H}_{2}$ & - & 2.12 & - & - & \\
\hline$* \mathrm{H}_{2} \mathrm{O}$ & $\begin{array}{l}0.51,0.57,0.65,0.72 \\
0.82,0.94\end{array}$ & $1.13,1.38,1.9,2.69$ & 6.2 & continuum & \\
\hline $\mathrm{H}_{2} \mathrm{~S}$ & - & $2.5^{b}, 3.8$ & 7.7 & - & $\begin{array}{l}1.3,1.6,2.0, \\
2.6,4.1\end{array}$ \\
\hline $\mathrm{H}_{3}^{+}$ & - & $2.0,3-4.5$ & - & - & \\
\hline $\mathrm{HCN}$ & - & 3.0 & - & 14.0 & 7.1 \\
\hline HDO & - & $2.7,3.67$ & 7.13 & - & \\
\hline $\mathrm{N}_{2} \mathrm{O}$ & - & $2.8,3.9,4.5$ & $7.7,8.5$ & - & \\
\hline $\mathrm{NH}_{3}$ & $0.55,0.65,0.93$ & $1.5,2,2.25,2.9, \mathbf{3 . 0}$ & $6.1, \mathbf{1 0 . 5}$ & - & \\
\hline $\mathrm{NO}_{2}$ & - & 3.4 & $6.2,7.7$ & 13.5 & \\
\hline $\mathrm{O}_{2}$ & $0.58,0.69,0.76,1.27$ & - & - & - & $1.07,6.25$ \\
\hline $\mathrm{O}_{3}$ & $\begin{array}{l}0.45-0.75 \text { (the Chap- } \\
\text { puis band) }\end{array}$ & 4.7 & $9.1^{b}, 9.6$ & 14.3 & 3.3 \\
\hline $\mathrm{PH}_{3}$ & - & 4.3 & $8.9,10.1$ & - & \\
\hline $\mathrm{SO}_{2}$ & - & 4 & $7.3,8.8$ & - & \\
\hline $\mathrm{TiH}$ & $0.4-1$ & $1-1.6$ & - & - & \\
\hline $\mathrm{TiO}$ & $0.4-1$ & $1-3.5$ & - & - & \\
\hline VO & $0.4-1$ & $1-2.5$ & - & - & \\
\hline $\mathrm{Ca}$ & $\begin{array}{ll}0.8498, & 0.8542, \\
0.8662 & \end{array}$ & & - & - & \\
\hline $\mathrm{He}$ & - & 1.083 & - & - & \\
\hline$* \mathrm{~K}$ & 0.76 & - & - & - & \\
\hline$* \mathrm{Na}$ & 0.589 & 1.2 & - & - & \\
\hline Rayleigh & $0.4-1$ & - & - & - & \\
\hline Cloud/haze & yes & possible & silicates, etc. & - & \\
\hline $\mathrm{H} \mathrm{H} \alpha$ & 0.66 & & & & \\
\hline $\mathrm{H} \mathrm{H} \beta$ & 0.486 & & & & \\
\hline
\end{tabular}




\section{Status}

The spectroscopic properties of the atomic species listed in Table 1 namely $\mathrm{Na}, \mathrm{K}$, $\mathrm{H} \mathrm{H} \alpha, \mathrm{H} \mathrm{H} \beta, \mathrm{He}, \mathrm{Ca}$, are all well known and can be found in standard data sources such as NIST (see http://www.nist.gov/pml/data/asd.cfm).

Details of the methodology required for the construction of molecular line lists valid for extended ranges of temperatures and wavelengths has been discussed elsewhere [15, 19,20] and will not be repeated here. We also point the reader to recent work on the use high-accuracy, ab initio dipole moment surfaces for such studies [21, 22,23] Below we consider in turn each molecular species listed in Table 1

$\mathbf{C}_{2} \mathbf{H}_{2}$ : Extensive experimental work on acetylene has been performed in Brussels, see Moudens et al. [24] for example, and a line list based on this work is promised. Initial theoretical studies have been performed in London [25] and a full line list is planned as part of the ExoMol project. At least one line list should be available in due course.

$\mathbf{C}_{2} \mathbf{H}_{4}$ : there is no hot line list for ethylene. Work on a hot line list for this molecule is in progress as part of the ExoMol project [26]. A full line list should be available soon. Experimental (room-temperature) line lists are available for the low frequencies region, below $2400 \mathrm{~cm}^{-1}$, only [27,28]

$\mathbf{C}_{2} \mathbf{H}_{6}$ : there is no hot line list for ethane. One is planned as part of the ExoMol project and some preliminary calculations have been performed [29]. Ethane has 8 atoms and a low energy vibrational mode, so the number of lines at elevated temperatures are likely to be unmanageable. Experimentally (room-temperature) only the region the infrared active fundamental transitions from the three main spectral regions, around $12 \mu \mathrm{m}$ [30], $6.2-7.5 \mu \mathrm{m}$ [31], and 3.3 $\mu \mathrm{m}$ [32] are covered. The proposal will be therefore to provide temperature-dependent cross sections [33] for ethane; these should be available in due course.

$\mathbf{C H}_{3} \mathbf{D}$ : There are no good current line lists for singly deuterated methane and the problem is harder than methane itself. A room-temperature line list for the $3 \mu \mathrm{m}$ region, important because it is in the window of the strong $\mathrm{CH}_{4}$ absorption, is available [34]. Work is a more comprehensive $\mathrm{CH}_{3} \mathrm{D}$ line list, appropriate for higher temperatures, is planned both as part of the ExoMol project and elsewhere. A hot line list for $\mathrm{CH}_{3} \mathrm{D}$ should be available in due course.

$\mathbf{C H}_{4}$ : Despite the detection of methane in HD189733b [35] and elsewhere [36 37,38], it has been recognised that the spectroscopic data for methane was inadequate for such studies [39,40,41,42]. The requirements for fully characterising the methane at the temperatures found in hot Jupiters are very demanding. A number of groups [43, 44, 45, 46, 47, 48, 49, 50] have been or are attempting to address this problem. Very recently we have computed a comprehensive line list for methane [16] which is known as 10 to 10 since it contains just under 10 billion lines. This line list has been demonstrated to give excellent results in detailed studies of bright T4.5 brown 
dwarf 2MASS 0559-14 [51]. The 10to10 line list is designed to model methane spectra for temperatures up to $1500 \mathrm{~K}$ but will require further work to be complete for higher temperatures and to improve the representation of the spectrum at short wavelengths.

CO: HITEMP contains an extensive CO line list constructed using laboratory and sunspot spectra. These should be sufficient for exoplanetary work. However, there has been recent work on IR spectrum [52,53,54] and the hot VUV spectra [55]. The ExoMol project is planning new line lists which should both provide data for all $\mathrm{CO}$ isotopologues and increase the range of the line list to all bound-bound rotationvibration transitions which is important for studies of hotter objects such as cool stars.

$\mathbf{C O}_{2}$ : HITEMP contains a comprehensive line list for carbon dioxide. However this line list has been subsequently improved and extended [56]. This new line list should be sufficient for exoplanet studies although other sources of $\mathrm{CO}_{2}$ data have become available for both infrared [57,58,59] and ultraviolet wavelengths [60].

FeH: Experimental partial line lists are available [61], further observational data is available from high resolution studies of M-dwarf star [62,63] and sunspot [64] spectra. These data will be used by ExoMol to make a comprehensive line list.

$\mathbf{H}_{2}$ : A comprehensive line list for this molecule covering bound-bound transitions has recently been constructed [65]. A new version of the important continuum induced absorption (CIA) has also been released [66]. These datasets should be sufficient for exoplanet studies.

$\mathbf{H}_{2} \mathbf{O}$ : The BT2 line list [67] was used to make the original identification of water in HD189733b [68]. Subsequently the BT2 line list was used as the basis for water in the HITEMP, which also made use of the available laboratory data. Although work is continuing on improving the representation of water [69,70,71], the data in HITEMP is both comprehensive and accurate, and should prove the required spectroscopic data.

$\mathbf{H}_{2} \mathbf{S}$ : Hydrogen sulphide is being studied as part of the ExoMol project. A full, high temperature line list, which will be be sufficient for exoplanetary studies, has just been completed [72].

$\mathbf{H}_{3}^{+}$: A comprehensive line list for $\mathrm{H}_{3}^{+}$was provided some time ago [73] and has already been used for exoplanetary studies [74]. A new, upgraded line list based on an improved theoretical treatment of this molecule [75,76] is likely to become available fairly soon; however the available line list is already sufficient for exoplanet studies as confirmed by recent experimental tests [75,77].

HCN: Line lists for hydrogen cyanide were some of the first calculated using variational nuclear motion calculations [78,79]. However these line lists are purely ab initio and do not give accurate wavelengths. Harris et al. [80] improved their line 
list, which covers both $\mathrm{HCN}$ and $\mathrm{HNC}$, using the then experimental data. A similar technique was used to create line list for $\mathrm{H}^{13} \mathrm{CN}$ and $\mathrm{HN}^{13} \mathrm{C}$ [81]. Mellau subsequently performed very extensive experimental studies on both hot $\mathrm{HCN}$ and hot HNC [82,83]. A greatly improved version of the Harris et al line list has been constructed using Mellau's energy levels as part of the ExoMol project [84]. This line list should be sufficient for exoplanet studies.

HDO: The VTT line list [85] provides a line list for deuterated water of a quality similar to that of BT2. The accuracy of VTT can be further improved using experimental data [86, 87] but is probably already sufficient for planned exoplanet studies.

$\mathbf{N}_{2} \mathbf{O}$ : A theoretical, approximate hot line list in the $4.5 \mu \mathrm{m}$ region has been constructed [88]. A very comprehensive room temperature line list for $\mathrm{N}_{2} \mathrm{O}$ is provided by the HITRAN data base [11] using laboratory covering all frequency ranges required. These data should be extended to elevated temperatures.

$\mathbf{N H}_{3}$ : Extensive line lists for ammonia are available [89,90]. The BYTe line list [90] was explicitly designed with the needs of exoplanet spectroscopy in mind. This line list has already been used for modelling spectra of brown dwarfs [9,91] and it should be sufficient for exoplanet studies.

$\mathrm{NO}_{2}$ : A room temperature line list for $\mathrm{NO}_{2}$ is provided by the HITRAN data base [11] and is constructed using laboratory covering the frequency range required EChO. These data should be extended to elevated temperatures.

$\mathbf{O}_{2}$ : Oxygen spectra have been subject to renewed experimental studied including work at higher temperatures. This work is captured in the analysis of Yu et al. [92], which should be sufficient for exoplanet studies.

$\mathbf{O}_{3}$ : The spectrum of ozone has been studied systematically over many years in Rheims, France. This data is captured in the SMPO (Spectroscopy \& Molecular Properties of Ozone) database [93], which is also accessible as part of the VAMDC project [94]. This line list should be sufficient for exoplanet studies.

$\mathbf{P H}_{3}$ : Phosphine is being studied as part of the ExoMol project. An initial line list has recently been released [95]. A full, high temperature line list, which will be be sufficient for exoplanetary studies, has just been completed [96]. A more limited, below $3600 \mathrm{~cm}^{-1}$ only, room-temperature, empirical line list is also available for $\mathrm{PH}_{3}$ [97].

$\mathbf{S O}_{2}$ :A line list for $\mathrm{SO}_{2}$ has recently been computed at NASA Ames [98]. This line list is for temperatures appropriate to solar system planets (notably Venus). A full high temperature line list, which will be sufficient for exoplanetary studies, is being computed as a collaboration between ExoMol and NASA Ames. 
TiH: A partial, empirical line list for TiH is available [99]. Work is in progress as part of the ExoMol project [100] producing a comprehensive line list which will be sufficient for exoplanet studies.

TiO: A very extensive, hot line list for TiO was constructed by Schwenke [101] using a mixture of empirical data and $a b$ initio calculations. However, subsequent experimental work on this system [102,103, 104] has led to the suggestion both this and other [105] line lists are incomplete. Despite this criticism, Schwenke's line list has so far proved sufficient for exoplanetary studies. Given the known importance of TiO in the spectra of M-dwarf stars [106], this problem probably needs to be re-visited.

VO: Partial experimental line lists are available [107, 108]. Work is already under way in the ExoMol project which will use this data to make a comprehensive line list.

\section{Other species}

The radicals NO and OH are well-known in the Earth's atmosphere but are not considered in Table 1. Both are included in HITEMP [14] and they should be included in any comprehensive spectroscopic database.

NO: The HITEMP hot line list was constructed using laboratory (lower excitations) and extrapolated (high $v, J$ ) data. NO is characterised by absorption features at 1.1, 1.36, 1.80, 2.7, $5.3 \mu \mathrm{m}$. The HITEMP line list should be sufficient for exoplanet studies.

OH: $\mathrm{OH}$ shows absorption features at 1.0, 1.43, $2.8 \mu \mathrm{m}$. The HITEMP line list should be sufficient for exoplanet studies.

Apart from the molecules listed above, ExoMol is undertaking work on line lists for molecules with the potential to become important for exoplanetary atmospheric modelling. Some of such molecules are listed below.

SiO: ExoMol has released a comprehensive line list which will be sufficient for studies of the atmospheres of exoplanets and stars [109].

BeH, MgH and CaH: ExoMol has released comprehensive hot line lists for these species [110].

$\mathbf{H C l}, \mathbf{N a C l}$ and $\mathbf{K C l}$ : are likely to be the main chlorine-bearing species in exoplanets. A new empirically-derived line list for $\mathrm{HCl}$ has been provided by Gordon et al. [111,112] which tests show is sufficient for studies at elevated temperatures. New line lists for $\mathrm{NaCl}$ and $\mathrm{KCl}$ have been constructed as part of the ExoMol project [113]. 
$\mathbf{S O}_{3}$ : A room temperature line list has been released by ExoMol [114] and a full, high-temperature list is nearly complete.

$\mathbf{H}_{2} \mathbf{C O}$ : A high temperature line list for formaldehyde has just been completed as part of the ExoMol project [115].

AlH, AlO, $\mathrm{C}_{2}, \mathrm{C}_{3}, \mathrm{CaO}, \mathrm{CrH}, \mathrm{CS}, \mathrm{HNO}_{3}, \mathrm{NaH}, \mathrm{NiH}, \mathrm{PN}, \mathrm{ScH}, \mathrm{SH}, \mathrm{SiH}$ : Work is under way in the ExoMol project on these molecules.

There are of course many other species that it may become necessary to consider including, for example, larger hydrocarbons. Thus, it has has been suggested that methanol should provide a useful temperature probe in methane-rich brown dwarfs [116]. Partial line lists are available for methanol [117,118] although the main focus of these studies is for identifying the highly complex spectrum of methanol observed in the interstellar medium.

\section{Conclusions}

The EChO mission and other possible attempts to characterise the atmospheres of exoplanets using spectroscopy place very significant demands on the laboratory data for spectroscopic interpretation of the observations. Assembling all the required data requires considerable effort on the part of laboratory astrophysicists. Much of this data is already available and can be found on the ExoMol website (www.exomol.com). Plans for the compiling line lists for the remaining molecules on an appropriate time scale for the EChO mission are well under way. This information can be used to construct a mission-specific spectroscopic database prior to any launch. These data are available in a variety of formats [33] and can be presented in a format suitable for use in mission-specific software such as EChOSIM [119].

Acknowledgements This work was supported by ERC Advanced Investigator Project 267219 and STFC.

\section{References}

1. G. Tinetti, J. Beaulieu, T. Henning, M. Meyer, G. Micela, I. Ribas, D. Stam, M. Swain, O. Krause, M. Ollivier, E. Pace, B. Swinyard, A. Aylward, R. van Boekel, A. Coradini, T. Encrenaz, I. Snellen, M.R. Zapatero-Osorio, J. Bouwman, J.Y.K. Cho, V. Coudé du Foresto, T. Guillot, M. Lopez-Morales, I. Mueller-Wodarg, E. Palle, F. Selsis, A. Sozzetti, P.A.R. Ade, N. Achilleos, A. Adriani, C.B. Agnor, C. Afonso, C. Allende Prieto, G. Bakos, R.J. Barber, M. Barlow, V. Batista, P. Bernath, B. Bézard, P. Bordé, L.R. Brown, A. Cassan, C. Cavarroc, A. Ciaravella, C. Cockell, A. Coustenis, C. Danielski, L. Decin, R. De Kok, O. Demangeon, P. Deroo, P. Doel, P. Drossart, L.N. Fletcher, M. Focardi, F. Forget, S. Fossey, P. Fouqué, J. Frith, M. Galand, P. Gaulme, J.L. González Hernàndez, O. Grasset, D. Grassi, J.1. Grenfell, M. Griffin, C.A. Griffith, U. Grözinger, M. Guedel, P. Guio, O. Hainaut, R. Hargreaves, P.H. Hauschildt, K. Heng, D. Heyrovsky, R. Hueso, P. Irwin, L. Kaltenegger, P. Kervella, D. Kipping, T.T. Koskinen, G. Kovács, A. La Barbera, H. Lammer, E. Lellouch, G. Leto, M. Lopez Morales, M.A. Lopez Valverde, M. Lopez-Puertas, C. Lovis, A. Maggio, J.P. Maillard, J. Maldonado Prado, J.B. Marquette, F. Martin-Torres, P. Maxted, S. Miller, S. Molinari, D. Montes, A. Moro-Martin, J.L. Moses, O. Mousis, N. Nguyen Tuong, R. Nelson, G.S. Orton, E. Pantin, E. Pascale, S. Pezzuto, D. Pinfield, E. Poretti, R. Prinja, L. Prisinzano, J.M. Rees, A. Reiners, B. Samuel, 
A. Sánchez-Lavega, J. Sanz Forcada, D. Sasselov, G. Savini, B. Sicardy, A. Smith, L. Stixrude, G. Strazzulla, J. Tennyson, M. Tessenyi, G. Vasisht, S. Vinatier, S. Viti, I. Waldmann, G.J. White, T. Widemann, R. Wordsworth, R. Yelle, Y. Yung, S.N. Yurchenko, Exp. Astron. 34, 311 (2012)

2. P.G.J. Irwin, N.A. Teanby, R. de Kok, L.N. Fletcher, C.J.A. Howett, C.C.C. Tsang, C.F. Wilson, S.B. Calcutt, C.A. Nixon, P.D. Parrish, J. Quant. Spectrosc. Radiat. Transf. 109, 1136 (2008). DOI 10.1016/j.jqsrt.2007.11.006

3. M.D.J. Hollis, M. Tessenyi, G. Tinetti, Comput. Phys. Commun. 184(10), 2351 (2013). DOI 10. 1016/j.cpc.2013.05.011

4. N. Madhusudhan, S. Seager, ApJ 707, 24 (2009)

5. R.L. Kurucz, in SAO Special Report, vol. 309 (1970), vol. 309, p. 292 . URL http://kurucz.harvard.edu/papers/SA0309

6. B. Gustafsson, B. Edvardsson, K. Eriksson, U.G. Jorgensen, A. Nordlund, B. Plez, A\&A 486, 951 (2008). DOI 10.1051/0004-6361:200809724

7. P.H. Hauschildt, E. Baron, J. Comput. Appl. Math. 109, 41 (1999). DOI 10.1016/S0377-0427(99) 00153-3

8. F. Allard, N.F. Allard, D. Homeier, J. Kielkopf, M.J. McCaughrean, F. Spiegelman, A\&A 474, L21 (2007). DOI 10.1051/0004-6361:20078362

9. J. Bailey, L. Kedziora-Chudczer, MNRAS 419, 1913 (2012). DOI \{10.1111/j.1365-2966.2011. 19845.x\}

10. L.S. Rothman, I.E. Gordon, A. Barbe, D.C. Benner, P.F. Bernath, M. Birk, V. Boudon, L.R. Brown, A. Campargue, J.P. Champion, K. Chance, L.H. Coudert, V. Dana, V.M. Devi, S. Fally, J.M. Flaud, R.R. Gamache, A. Goldman, D. Jacquemart, I. Kleiner, N. Lacome, W.J. Lafferty, J.Y. Mandin, S.T. Massie, S.N. Mikhailenko, C.E. Miller, N. Moazzen-Ahmadi, O.V. Naumenko, A.V. Nikitin, J. Orphal, V.I. Perevalov, A. Perrin, A. Predoi-Cross, C.P. Rinsland, M. Rotger, M. Simeckova, M.A.H. Smith, K. Sung, S.A. Tashkun, J. Tennyson, R.A. Toth, A.C. Vandaele, J. Vander Auwera, J. Quant. Spectrosc. Radiat. Transf. 110, 533 (2009)

11. L.S. Rothman, I.E. Gordon, Y. Babikov, A. Barbe, D.C. Benner, P.F. Bernath, M. Birk, L. Bizzocchi, V. Boudon, L.R. Brown, A. Campargue, K. Chance, E.A. Cohen, L.H. Coudert, V.M. Devi, B.J. Drouin, A. Fayt, J.M. Flaud, R.R. Gamache, J.J. Harrison, J.M. Hartmann, C. Hill, J.T. Hodges, D. Jacquemart, A. Jolly, J. Lamouroux, R.J. Le Roy, G. Li, D.A. Long, O.M. Lyulin, C.J. Mackie, S.T. Massie, S. Mikhailenko, H.S.P. Mller, O.V. Naumenko, A.V. Nikitin, J. Orphal, V. Perevalov, A. Perrin, E.R. Polovtseva, C. Richard, M.A.H. Smith, E. Starikova, K. Sung, S. Tashkun, J. Tennyson, G.C. Toon, V.G. Tyuterev, G. Wagner, J. Quant. Spectrosc. Radiat. Transf. 130, 4 (2013). DOI 10.1016/jqsrt.2013.07.002

12. N. Jacquinet-Husson, L. Crepeau, R. Armante, C. Boutammine, A. Chédin, N.A. Scott, C. Crevoisier, V. Capelle, C. Boone, N. Poulet-Crovisier, A. Barbe, A. Campargue, D.C. Benner, Y. Benilan, B. Bézard, V. Boudon, L.R. Brown, L.H. Coudert, A. Coustenis, V. Dana, V.M. Devi, S. Fally, A. Fayt, J.M. Flaud, A. Goldman, M. Herman, G.J. Harris, D. Jacquemart, A. Jolly, I. Kleiner, A. Kleinböhl, F. Kwabia-Tchana, N. Lavrentieva, N. Lacome, L.H. Xu, O.M. Lyulin, J.Y. Mandin, A. Maki, S. Mikhailenko, C.E. Miller, T. Mishina, N. Moazzen-Ahmadi, H.S.P. Müller, A. Nikitin, J. Orphal, V. Perevalov, A. Perrin, D.T. Petkie, A. Predoi-Cross, C.P. Rinsland, J.J. Remedios, M. Rotger, M.A.H. Smith, K. Sung, S. Tashkun, J. Tennyson, R.A. Toth, A.C. Vandaele, J. Vander Auwera, J. Quant. Spectrosc. Radiat. Transf. 112, 2395 (2011)

13. R.L. Kurucz, Can. J. Phys. 89, 417 (2011)

14. L.S. Rothman, I.E. Gordon, R.J. Barber, H. Dothe, R.R. Gamache, A. Goldman, V.I. Perevalov, S.A. Tashkun, J. Tennyson, J. Quant. Spectrosc. Radiat. Transf. 111, 2139 (2010)

15. J. Tennyson, S.N. Yurchenko, MNRAS 425, 21 (2012)

16. S.N. Yurchenko, J. Tennyson, MNRAS (2014)

17. The EChO Consortium, EChO Exoplanet Characterisation Observatory: Exploring Atmospheres of Diverse Worlds Beyond our Solar System (proposal submitted to ESA on Dec. 3rd, 2010 in response to call to M3 missions (2010)

18. EChO Science Study Team, EChO: Exploring the atmospheres of diverse worlds beyond our Solar System. European Space Agency (2013)

19. L. Lodi, J. Tennyson, J. Phys. B: At. Mol. Opt. Phys. 43, 133001 (2010)

20. J. Tennyson, WIREs Comput. Mol. Sci. 2, 698 (2012). DOI 10.1002/wcms.94

21. S.N. Yurchenko, in Chemical Modelling: Volume 10, vol. 10 (The Royal Society of Chemistry, 2014), pp. 183-228. DOI 10.1039/9781849737241-00183. URL http://dx.doi.org/10.1039/9781849737241-00183 
22. L. Lodi, J. Tennyson, J. Quant. Spectrosc. Radiat. Transf. 113, 850 (2012)

23. J. Tennyson, J. Mol. Spectrosc. 296, 1 (2014)

24. A. Moudens, R. Georges, A. Benidar, B. Amyay, M. Herman, A. Fayt, B. Plez, J. Quant. Spectrosc. Radiat. Transf. 112, 540 (2011)

25. A. Urru, I.N. Kozin, G. Mulas, B.J. Braams, J. Tennyson, Mol. Phys. 108, 1973 (2010)

26. A.I. Pavlyuchko, A. Yachmenev, J. Tennyson, S.N. Yurchenko (2014). (work in progress)

27. J.M. Flaud, W.J. Lafferty, R. Sams, V.M. Devi, J. Mol. Spectrosc. 259, 39 (2010). DOI 10.1016/j. jms.2009.10.003

28. W.J. Lafferty, J.M. Flaud, F.K. Tchana, Mol. Phys. 109, 2501 (2011). DOI 10.1080/00268976.2011. 577040

29. A.I. Pavlyuchko, J. Tennyson, S.N. Yurchenko (2014). (work in progress)

30. J.V. Auwera, N. Moazzen-Ahmadi, J.M. Flaud, ApJ 662(1, 1), 750 (2007)

31. F. Lattanzi, C. di Lauro, J.V. Auwera, J. Mol. Spectrosc. 248(2), 134 (2008). DOI 10.1016/j.jms. 2007.12.006

32. F. Lattanzi, C. di Lauro, J. Vander Auwera, J. Mol. Spectrosc. 267(1-2, SI), 71 (2011). DOI 10.1016/ j.jms.2011.02.003

33. C. Hill, S.N. Yurchenko, J. Tennyson, Icarus 226, 1673 (2013)

34. A.V. Nikitin, J.P. Champion, L.R. Brown, J. Mol. Spectrosc. 240, 14 (2006). DOI 10.1016/j.jms. 2006.08.002

35. M.R. Swain, G. Vasisht, G. Tinetti, Nature 452(7185), 329 (2008). DOI 10.1038/nature06823

36. M.R. Swain, P. Deroo, C.A. Griffith, G. Tinetti, A. Thatte, G. Vasisht, P. Chen, J. Bouwman, I.J. Crossfield, D. Angerhausen, C. Afonso, T. Henning, Nature 463, 637 (2010)

37. M. Janson, J. Carson, C. Thalmann, M.W. McElwain, M. Goto, J. Crepp, J. Wisniewski, L. Abe, W. Brandner, A. Burrows, S. Egner, M. Feldt, C.A. Grady, T. Golota, O. Guyon, J. Hashimoto, Y. Hayano, M. Hayashi, S. Hayashi, T. Henning, K.W. Hodapp, M. Ishii, M. Iye, R. Kandori, G.R. Knapp, T. Kudo, N. Kusakabe, M. Kuzuhara, T. Matsuo, S. Mayama, S. Miyama, J.I. Morino, A. Moro-Martin, T. Nishimura, T.S. Pyo, E. Serabyn, H. Suto, R. Suzuki, M. Takami, N. Takato, H. Terada, B. Tofflemire, D. Tomono, E.L. Turner, M. Watanabe, T. Yamada, H. Takami, T. Usuda, M. Tamura, ApJ 728, 85 (2011). DOI $\{10.1088 / 0004-637 X / 728 / 2 / 85\}$

38. J.P. Beaulieu, G. Tinetti, D. Kipping, I. Ribas, R.J. Barber, J.Y.K. Cho, I. Polichtchouk, J. Tennysson, S.N. Yurchenko, C.A. Griffith, I. Waldmann, S. Miller, S. Carey, O. Mousis, S.J. Fossey, A. Aylward, ApJ 731, 16 (2011)

39. B.M. Dinelli, S. Miller, N. Achilleos, H.A. Lam, M. Cahill, J. Tennyson, M.F. Jagod, T. Oka, J.C. Hilico, T.R. Geballe, Icarus 126, 107 (1997)

40. C.M. Sharp, A. Burrows, ApJS 168(1), 140 (2007)

41. R.S. Freedman, M.S. Marley, K. Lodders, ApJS 174(2), 504 (2008). DOI 10.1086/521793

42. J. Bailey, L. Ahlsved, V.S. Meadows, Icarus 213, 218 (2011). DOI \{10.1016/j.icarus.2011.02.009\}

43. D.W. Schwenke, H. Partridge, Spectra Chimica Acta A 57, 887 (2001). DOI 10.1016/ S1386-1425(00)00451-0

44. D.W. Schwenke, Spectra Chimica Acta A 58, 849 (2002). DOI 10.1016/S1386-1425(01)00673-4

45. R. Warmbier, R. Schneider, A.R. Sharma, B.J. Braams, J.M. Bowman, P.H. Hauschildt, A\&A 495, 655 (2009). DOI 10.1051/0004-6361:200810983

46. Y.A. Ba, C. Wenger, R. Surleau, V. Boudon, M. Rotger, L. Daumont, D.A. Bonhommeau, V.G. Tyuterev, M.L. Dubernet, J. Quant. Spectrosc. Radiat. Transf. pp. 62-68 (2013). DOI http://dx.doi. org/10.1016/j.jqsrt.2013.05.001

47. X.G. Wang, T. Carrington, Jr., J. Chem. Phys. 138, 104106 (2013). DOI $\{10.1063 / 1.4793474\}$

48. S.L. Mielke, A. Chakraborty, D.G. Truhlar, J. Phys. Chem. A 117, 7327 (2013). DOI 10.1021/ jp4011789

49. M. Rey, A.V. Nikitin, V.G. Tyuterev, Phys. Chem. Chem. Phys. 15, 10049 (2013). DOI 10.1039/ C3CP50275A

50. M. Rey, A.V. Nikitin, V.G. Tyuterev, J. Mol. Spectrosc. 291, 8597 (2013). DOI 10.1016/j.jms.2013. 04.003

51. S.N. Yurchenko, J. Tennyson, J. Bailey, M. Hollis, G. Tinetti, PNAS (2014)

52. S.A. Tashkun, T.I. Velichko, S.N. Mikhailenko, J. Quant. Spectrosc. Radiat. Transf. 111, 1106 (2010). DOI $\{10.1016 /$ j.jqsrt.2010.01.026\}

53. T.I. Velichko, S.N. Mikhailenko, S.A. Tashkun, J. Quant. Spectrosc. Radiat. Transf. 113, 1643 (2012). DOI $\{10.1016 /$ j.jqsrt.2012.04.014 $\}$

54. J.A. Coxon, P.G. Hajigeorgiou, J. Quant. Spectrosc. Radiat. Transf. 116, 75 (2013). DOI \{10.1016/ j.jqsrt.2012.10.006\} 
55. A.M. Brandis, C.O. Johnston, B.A. Cruden, D.K. Prabhu, A.A. Wray, Y. Liu, D.W. Schwenke, D. Bose, J. Quant. Spectrosc. Radiat. Transf. 121, 91 (2013). DOI \{10.1016/j.jqsrt.2013.02.009\}

56. S.A. Tashkun, V.I. Perevalov, J. Quant. Spectrosc. Radiat. Transf. 112, 1403 (2011). DOI 10.1016/j. jqsrt.2011.03.005

57. X. Huang, D.W. Schwenke, S.A. Tashkun, T.J. Lee, J. Chem. Phys. 136, 124311 (2012)

58. X. Huang, R.S. Freedman, S.A. Tashkun, D.W. Schwenke, T.J. Lee, J. Quant. Spectrosc. Radiat. Transf. 130, 134 (2013). DOI 10.1016/j.jqsrt.2013.05.018

59. S. Stefani, G. Piccioni, M. Snels, D. Grassi, A. Adriani, J. Quant. Spectrosc. Radiat. Transf. 117, 21 (2013). DOI 10.1016/j.jqsrt.2012.11.019

60. O. Venot, N. Fray, Y. Benilan, M.C. Gazeau, E. Hebrard, G. Larcher, M. Schwell, M. Dobrijevic, F. Selsis, A\&A 551, A131 (2013). DOI 10.1051/0004-6361/201220945

61. M. Dulick, C.W. Bauschlicher, A. Burrows, C.M. Sharp, R.S. Ram, P. Bernath, ApJ 594, 651 (2003). DOI 10.1086/376791

62. R.J. Hargreaves, K.H. Hinkle, C.W. Bauschlicher, Jr., S. Wende, A. Seifahrt, P.F. Bernath, AJ. 140, 919 (2010). DOI 10.1088/0004-6256/140/4/919

63. S. Wende, A. Reiners, A. Seifahrt, P.F. Bernath, A\&A 523, A58 (2010). DOI 10.1051/0004-6361/ 201015220

64. D. Fawzy, New Astron. 14, 708 (2009). DOI 10.1016/j.newast.2009.05.004

65. A. Campargue, S. Kassi, K. Pachucki, J. Komasa, Phys. Chem. Chem. Phys. 14, 802 (2012). DOI $10.1039 / \mathrm{c} 1 \mathrm{cp} 22912 \mathrm{e}$

66. C. Richard, I.E. Gordon, L.S. Rothman, M. Abel, L. Frommhold, M. Gustafsson, J.M. Hartmann, C. Hermans, W.J. Lafferty, G.S. Orton, K.M. Smith, H. Tran, J. Quant. Spectrosc. Radiat. Transf. 113, 1276 (2012). DOI 10.1016/j.jqsrt.2011.11.004

67. R.J. Barber, J. Tennyson, G.J. Harris, R.N. Tolchenov, MNRAS 368, 1087 (2006)

68. G. Tinetti, A. Vidal-Madjar, M.C. Liang, J.P. Beaulieu, Y. Yung, S. Carey, R.J. Barber, J. Tennyson, I. Ribas, N. Allard, G.E. Ballester, D.K. Sing, F. Selsis, Nature 448, 169 (2007)

69. L. Lodi, J. Tennyson, O.L. Polyansky, J. Chem. Phys. 135, 034113 (2011)

70. J. Tennyson, P.F. Bernath, L.R. Brown, A. Campargue, M.R. Carleer, A.G. Császár, L. Daumont, R.R. Gamache, J.T. Hodges, O.V. Naumenko, O.L. Polyansky, L.S. Rothmam, A.C. Vandaele, N.F. Zobov, A.R. Al Derzi, C. Fábri, A.Z. Fazliev, T. Furtenbacher, I.E. Gordon, L. Lodi, I.I. Mizus, J. Quant. Spectrosc. Radiat. Transf. 117, 29 (2013)

71. O.L. Polyansky, R.I. Ovsyannikov, A.A. Kyuberis, L. Lodi, J. Tennyson, N.F. Zobov, J. Phys. Chem. A 117, 96339643 (2013). DOI 10.1021/jp312343z

72. A.A.A. Azzam, S.N. Yurchenko, J. Tennyson, MNRAS p. (in preparation) (2014)

73. L. Neale, S. Miller, J. Tennyson, ApJ 464, 516 (1996)

74. T.T. Koskinen, A.D. Aylward, S. Miller, Nature 450, 845 (2007)

75. M. Pavanello, L. Adamowicz, A. Alijah, N.F. Zobov, I.I. Mizus, O.L. Polyansky, J. Tennyson, T. Szidarovszky, A.G. Császár, M. Berg, A. Petrignani, A. Wolf, Phys. Rev. Lett. 108, 023002 (2012)

76. M. Pavanello, L. Adamowicz, A. Alijah, N.F. Zobov, I.I. Mizus, O.L. Polyansky, J. Tennyson, T. Szidarovszky, A.G. Császár, J. Chem. Phys. 136, 184303 (2012)

77. A. Petrignani, M. Berg, A. Wolf, I.I. Mizus, O.L. Polyansky, J. Tennyson, N.F. Zobov, M. Pavanello, L. Adamowicz, (2014)

78. K. Eriksson, B. Gustafsson, U.G. Jørgensen, A. Nordlund, A\&A 132, 37 (1984)

79. G.J. Harris, O.L. Polyansky, J. Tennyson, ApJ 578, 657 (2002)

80. G.J. Harris, J. Tennyson, B.M. Kaminsky, Y.V. Pavlenko, H.R.A. Jones, MNRAS 367, 400 (2006)

81. G.J. Harris, F.C. Larner, J. Tennyson, B.M. Kaminsky, Y.V. Pavlenko, H.R.A. Jones, MNRAS 390, 143 (2008)

82. G.C. Mellau, J. Chem. Phys. 134, 234303 (2011)

83. G.C. Mellau, J. Mol. Spectrosc. 269, 77 (2011)

84. R.J. Barber, J.K. Strange, C. Hill, O.L. Polyansky, G.C. Mellau, S.N. Yurchenko, J. Tennyson, MNRAS 437, 1828 (2014). DOI 10.1093/mnras/stt2011

85. B.A. Voronin, J. Tennyson, R.N. Tolchenov, A.A. Lugovskoy, S.N. Yurchenko, MNRAS 402, 492 (2010)

86. J. Tennyson, P.F. Bernath, L.R. Brown, A. Campargue, M.R. Carleer, A.G. Császár, L. Daumont, R.R. Gamache, J.T. Hodges, O.V. Naumenko, O.L. Polyansky, L.S. Rothman, R.A. Toth, A.C. Vandaele, N.F. Zobov, A.Z. Fazliev, T. Furtenbacher, I.E. Gordon, S.N. Mikhailenko, B.A. Voronin, J. Quant. Spectrosc. Radiat. Transf. 111, 2160 (2010)

87. N. N.Lavrentieva, B.A. Voronin, Y.G. Borkov, A. A.Fedorova, Icarus p. (in press) (2014) 
88. L. Rosenmann, B. Khalil, R. Le Doucen, J. Quant. Spectrosc. Radiat. Transf. 57, 477 (1997). DOI 10.1016/S0022-4073(96)00150-1

89. S.N. Yurchenko, R.J. Barber, A. Yachmenev, W. Thiel, P. Jensen, J. Tennyson, J. Phys. Chem. A 113, 11845 (2009)

90. S.N. Yurchenko, R.J. Barber, J. Tennyson, MNRAS 413, 1828 (2011)

91. P.W. Lucas, C.G. Tinney, B. Burningham, S.K. Leggett, D.J. Pinfield, R. Smart, H.R.A. Jones, F. Marocco, R.J. Barber, S.N. Yurchenko, J. Tennyson, M. Ishii, M. Tamura, A.C. Day-Jones, A. Adamson, F. Allard, D. Homeier, MNRAS 408, L56 (2010)

92. S. Yu, C.E. Miller, B.J. Drouin, H.S.P. Mueller, J. Chem. Phys. 137, 024304 (2012). DOI \{10.1063/ $1.4719170\}$

93. Y.L. Babikov, S.N. Mikhailenko, A. Barbe, V.G. Tyuterev, J. Quant. Spectrosc. Radiat. Transf. (2014)

94. M.L. Dubernet, V. Boudon, J.L. Culhane, M.S. Dimitrijevic, A.Z. Fazliev, C. Joblin, F. Kupka, G. Leto, P. Le Sidaner, P.A. Loboda, H.E. Mason, N.J. Mason, C. Mendoza, G. Mulas, T.J. Millar, L.A. Nunez, V.I. Perevalov, N. Piskunov, Y. Ralchenko, G. Rixon, L.S. Rothman, E. Roueff, T.A. Ryabchikova, A. Ryabtsev, S. Sahal-Brechot, B. Schmitt, S. Schlemmer, J. Tennyson, V.G. Tyuterev, N.A. Walton, V. Wakelam, C.J. Zeippen, J. Quant. Spectrosc. Radiat. Transf. 111, 2151 (2010)

95. C. Sousa-Silva, S.N. Yurchenko, J. Tennyson, J. Mol. Spectrosc. 288, 28 (2013)

96. C. Sousa-Silva, S.N. Yurchenko, J. Tennyson, MNRAS p. (in preparation) (2014)

97. A.V. Nikitin, J.P. Champion, R.A.H. Butler, L.R. Brown, I. Kleiner, J. Mol. Spectrosc. 256, 4 (2009)

98. X. Huang, D.W. Schwenke, T.J. Lee, J. Chem. Phys. 140(11), 114311 (2014). DOI http://dx.doi.org/10.1063/1.4868327. URL http://scitation.aip.org/content/aip/journal/jcp/140/11/10.1063/1.4868327

99. A. Burrows, M. Dulick, C.W. Bauschlicher, P.F. Bernath, R.S. Ram, C.M. Sharp, J.A. Milsom, ApJ 624, 988 (2005). DOI 10.1086/429366

100. L. Lodi, J. Tennyson, S.N. Yurchenko (2014). (work in progress)

101. D.W. Schwenke, Faraday Discuss. 109, 321 (1998). DOI 10.1039/a800070k

102. R.S. Ram, P.F. Bernath, M. Dulick, L. Wallace, ApJS 122, 331 (1999). DOI 10.1086/313212

103. K. Kobayashi, G.E. Hall, J.T. Muckerman, T.J. Sears, A.J. Merer, J. Mol. Spectrosc. 212, 133 (2002). DOI 10.1006/jmsp.2002.8543

104. K.C. Namiki, H. Ito, S.P. Davis, J. Mol. Spectrosc. 217, 173 (2003). DOI 10.1016/S0022-2852(02) 00027-9

105. R. Alvarez, B. Plez, A\&A 330, 1109 (1998)

106. F. Allard, P.H. Hauschildt, D. Schwenke, ApJ 540, 1005 (2000)

107. R.S. Ram, P.F. Bernath, S.P. Davis, A.J. Merer, J. Mol. Spectrosc. 211, 279 (2002). DOI 10.1006/ jmsp. 2001.8510

108. R.S. Ram, P.F. Bernath, J. Mol. Spectrosc. 229, 57 (2005). DOI 10.1016/j.jms.2004.08.014

109. E.J. Barton, S.N. Yurchenko, J. Tennyson, MNRAS 434, 14691475 (2013)

110. B. Yadin, T. Vaness, P. Conti, C. Hill, S.N. Yurchenko, J. Tennyson, MNRAS 425, 34 (2012)

111. G. Li, I.E. Gordon, R.J. Le Roy, P.G. Hajigeorgiou, J.A. Coxon, P.F. Bernath, L.S. Rothman, J. Quant. Spectrosc. Radiat. Transf. 121, 78 (2013). DOI 10.1016/j.jqsrt.2013.02.005

112. G. Li, I.E. Gordon, P.G. Hajigeorgiou, J.A. Coxon, L.S. Rothman, J. Quant. Spectrosc. Radiat. Transf. 130, 284 (2013). DOI 10.1016/j.jqsrt.2013.07.019

113. E.J. Barton, C. Chiu, S. Golpayegani, S.N. Yurchenko, J. Tennyson, D.J. Frohman, P.F. Bernath, MNRAS (2014)

114. D.S. Underwood, J. Tennyson, S.N. Yurchenko, Phys. Chem. Chem. Phys. 15, 10118 (2013)

115. J. Tennyson, P.F. Bernath, A. Campargue, A.G. Császár, L. Daumont, R.R. Gamache, J.T. Hodges, D. Lisak, O.V. Naumenko, L.S. Rothman, H. Tran, N.F. Zobov, J. Buldyreva, C.D. Boone, M.D. De Vizia, L. Gianfrani, J.M. Hartmann, R. McPheat, J. Murray, N.H. Ngo, O.L. Polyansky, D. Weidmann, Pure Appl. Chem. (2014). (submitted)

116. K. Lodders, B. Fegley, Icarus 155, 393 (2002). DOI http://dx.doi.org/10.1006/icar.2001.6740

117. L.H. Xu, J. Fisher, R.M. Lees, H.Y. Shi, J.T. Hougen, J.C. Pearson, B.J. Drouin, G.A. Blake, R. Braakman, J. Mol. Spectrosc. 251, 305 (2008). DOI \{10.1016/j.jms.2008.03.017\}

118. C.S. Brauer, K. Sung, J.C. Pearson, L.R. Brown, L.H. Xu, J. Quant. Spectrosc. Radiat. Transf. 113, 128 (2012). DOI $\{10.1016 / j$.jqsrt.2011.09.012\}

119. I.P. Waldmann, E. Pascale, B. Swinyard, G. Tinetti, A. Amaral-Rogers, L. Spencer, M. Tessenyi, M. Ollivier, V. Coudé du Foresto, MNRAS , (submitted) (2014) 